\title{
The Effect of In Vitro Oxidative Stress on the Female Rabbit Bladder Contractile Response and Antioxidant Levels
}

\author{
Lisa Malone, Catherine Schuler, Robert E. Leggett, and Robert M. Levin \\ Stratton VA Medical Center, Albany College of Pharmacy and Health Sciences, 115 Holland Avenue, Albany, NY 12208, USA \\ Correspondence should be addressed to Robert M. Levin; robert.levin@acphs.edu
}

Received 4 April 2013; Accepted 8 May 2013

Academic Editors: J. Kliment, A. Papatsoris, M. A. Salah, and V. Serretta

Copyright (C) 2013 Lisa Malone et al. This is an open access article distributed under the Creative Commons Attribution License, which permits unrestricted use, distribution, and reproduction in any medium, provided the original work is properly cited.

\begin{abstract}
Introduction. There are several bladder dysfunctions that are associated with oxidative stress to the urinary bladder. Two experimental models are known to cause this type of bladder damage. The first is direct oxidative damage caused by hydrogen peroxide $\left(\mathrm{H}_{2} \mathrm{O}_{2}\right)$. The second is oxidative damage caused by ischemia followed by reperfusion (I/R). The specific aim of this study is to directly compare these two models of oxidative stress. Methods. Six adult female NZW rabbits were divided into two groups of three rabbits each. Eight full thickness strips from three rabbit bladders were taken for in vitro ischemia/reperfusion physiological analysis, while eight strips from three rabbit bladders were taken for in vitro $\mathrm{H}_{2} \mathrm{O}_{2}$ physiological analysis. All tissue was analyzed for total antioxidant activity (AA) and malondialdehyde (MDA) levels. In addition, samples of the water baths were also analyzed for AA. Results. In vitro I/R reduced the response to field stimulation (FS) to a significantly greater extent than the inhibition of the response to carbachol. In vitro $\mathrm{H}_{2} \mathrm{O}_{2}$ decreased all responses to approximately the same degree. Total AA levels at higher concentrations of $\mathrm{H}_{2} \mathrm{O}_{2}$ for all bath fluids were significantly higher than controls. MDA levels were significantly elevated in both models of oxidative stress.
\end{abstract}

\section{Introduction}

There are several lower urinary tract dysfunctions (LUTD) that are more prevalent in women than men including interstitial cystitis, recurrent urinary tract infections, and incontinence $[1,2]$. The bladder is composed of a thick smooth muscle wall. The inner most tissue layer of the bladder wall, the mucosa (urothelium), is intimately associated with lower urinary tract function [3]. The mucosa is the first line of defense against bladder infections and the penetration of urine solutes into the bladder tissue. The glycosaminoglycan coating of the mucosal surface presents a nonadherent surface to most strains of bacteria and an impermeable barrier to urinary solutes [4-7]. We believe that incontinence, recurrent urinary tract infections, and interstitial cystitis are related directly to estrogen levels. Low estrogen can induce a significant decrease in blood flow to the bladder especially in the mucosa resulting in free radical generation (oxidative stress) and a breakdown in mucosal integrity [8-10]. The etiology of these dysfunctions involves an increase in urothelial permeability and the movement of urinary solutes such as ions and other caustic substances from the urine into the mucosa, submucosa, and muscle. This results in both the increased permeability and free radical damage to cellular and subcellular membranes including the mitochondria, sarcoplasmic reticulum, and synaptic membranes [11, 12].

Beneath the urothelium and sometimes protruding through the basal laminae is a rich network of capillaries, the suburothelial capillary plexus [13]. Our current studies, and those of others, show that urothelial function is severely compromised by both ischemia and hypoxia $[3,10$, 14]. Furthermore, in vitro and in vivo rabbit models have demonstrated that bladder distention in the presence of mild hypoxia and ischemia causes increased mucosal permeability [15] and the generation of reactive oxygen species of free radicals (ROS) and reactive nitrogen species of free radicals (RNS) [16]. These factors together suggest that mucosal permeability is related to relative changes in oxygen tension and reduced blood flow. There is a significant reduction in local blood flow to the mucosa in patients with interstitial cystitis (IC) when compared with non-IC patients especially 
during bladder distention $[17,18]$. Clinically, the symptoms of pain and urgency of patients with IC are induced by distention and relieved by voiding of the bladder. We believe this is because ischemia and hypoxia of the bladder can affect sensory nerve membranes which lead to pain activation. These data are consistent with the hypothesis that bladder distention induces relative mucosal ischemia which increases mucosal permeability and the generation of free radicals [8].

As mentioned above, alterations in estrogen levels can significantly affect bladder blood flow to the lower urinary tract as it does to the vagina and uterus. Estrogen has been shown to increase blood flow to the bladder and urethra, while low estrogen reduces blood flow below normal inducing ischemia and hypoxia $[9,10,14]$. Studies have demonstrated that ovariectomy in rabbits results in a significant decrease in blood flow to the bladder detrusor smooth muscle and mucosa. This caused increased mucosal permeability, increased free radical generation, decreased bladder and urethral contraction, and decreased bladder function $[8,19]$. However, estrogen administration to ovariectomized rabbits resulted in the relief of mucosal and detrusor hypoxia, mucosal hyperplasia, and restoration of the mucosal permeability barrier as well as reduced oxidative stress $[9,10,14]$.

We utilize two in vitro models of oxidative damage. In the first model of ischemia/reperfusion (I/R), isolated strips of bladder are subjected to ischemic conditions by exposure to media equilibrated with nitrogen instead of oxygen and without glucose for a period of time. The strips are then allowed to recover in the presence of oxygen and glucose to simulate reperfusion [20]. The second model involves the direct exposure of isolated bladder strips to hydrogen peroxide $\left(\mathrm{H}_{2} \mathrm{O}_{2}\right)$. This would occur physiologically if the activity of superoxide dismutase (SOD) increased above the ability of catalase to neutralize the product of SOD activity, which is $\mathrm{H}_{2} \mathrm{O}_{2}$ [21].

Our specific aim of the current study is to directly compare the effects of exposure to $\mathrm{H}_{2} \mathrm{O}_{2}$ to that of $\mathrm{I} / \mathrm{R}$.

\section{Materials and Methods}

All methods were approved by the Institutional Animal Care and Use Committee of the Stratton VA Medical Center, Albany, NY, USA.

2.1. Animal Methods. Six adult female New Zealand white rabbits (approximately $3.5 \mathrm{~kg}$ each) were divided into two groups of three rabbits each. Each rabbit was anesthetized with $1-3 \%$ isoflurane. The bladder was rapidly removed and weighed and the rabbit euthanized with $2 \mathrm{~mL}$ fatal plus euthanasia fluid IV. Five strips of the bladder body and three strips of the base urethra from each bladder were taken for physiological testing. The balance of the bladder and urethra was separated by blunt dissection and frozen under liquid nitrogen and stored at $-80^{\circ} \mathrm{C}$ for biochemical analyses.

2.2. Physiological Analysis. Full thickness, longitudinal strips of the bladder body, and base-urethra were mounted in individual $15 \mathrm{~mL}$ baths containing oxygenated Tyrode's solution at $37^{\circ} \mathrm{C}$. Contractility studies on strips were performed as follows (in vitro $\mathrm{I} / \mathrm{R}$ experiment). Each strip was set at $2 \mathrm{~g}$ passive tension and stimulated with field stimulation (FS: $2 \mathrm{~Hz}, 8 \mathrm{~Hz}, 32 \mathrm{~Hz}, 1 \mathrm{~ms}$ duration for 20 seconds with 3 minutes in between stimulations). Carbachol $(20 \mu \mathrm{M})$ was then individually administered to each strip for a 3minute exposure followed by three washes 5 minutes apart with fresh buffer. Field stimulation was used to mimic neurotransmitter stimulation of muscle contraction through neurohumoral receptors. Carbachol is a muscarinic agonist stimulating the receptor directly without the participation of neurotransmission [8]. After control stimulations, the bath was then changed to Tyrode's solution without glucose and equilibrated with $95 \%$ nitrogen and $5 \%$ carbon dioxide for 1 hour with stimulation at $32 \mathrm{~Hz}$ every 5 minutes. The buffer was then changed back to normal, oxygenated Tyrode's with glucose, and the strips were allowed to recover for two hours. The strips were then stimulated as originally described and then cut, weighed, and frozen in liquid nitrogen for biochemical analyses. A sample of physiological buffer $(1 \mathrm{~mL})$ was taken after each stimulation and before and after the ischemic period.

Contractility studies on strips from the remaining three rabbit bladders were performed as follows (in vitro $\mathrm{H}_{2} \mathrm{O}_{2}$ experiment). The tissues were stimulated by field stimulation (FS: $2 \mathrm{~Hz}, 8 \mathrm{~Hz}, 32 \mathrm{~V}, 1 \mathrm{~ms}$ duration for 20 seconds with 3 minutes in between stimulations) and carbachol $(20 \mu \mathrm{M})$ individually administered to each strip for a 3-minute exposure. After carbachol, the strips were washed two times at 10-minute intervals with fresh, oxygenated Tyrode's solution. After the second wash, $0.1 \% \mathrm{H}_{2} \mathrm{O}_{2}$ was added for a ten-minute incubation, and the tissues were stimulated again by FS and carbachol. This process was repeated for $0.2 \%, 0.4 \%$, and $0.8 \%$ $\mathrm{H}_{2} \mathrm{O}_{2}$. A sample of physiological buffer $(1 \mathrm{~mL})$ was taken after each carbachol stimulation and frozen under liquid nitrogen for further biochemical analyses.

\subsection{Biochemical Analyses}

2.3.1. CUPRAC Assay. Total antioxidant levels of the tissue, experimental strips, and physiological buffer samples were quantified by the cupric ion reducing antioxidant capacity (CUPRAC) assay [22, 23].

2.3.2. Malondialdehyde Assay. Malondialdehyde levels of the tissue and experimental strips were quantified using a TBAbased assay $[24,25]$.

2.4. Statistical Analyses. One-way analysis of variance was used to determine if significant differences were present among the groups, and the Tukey test was used to compare individual groups. A $P<0.05$ was required for statistical significance. 


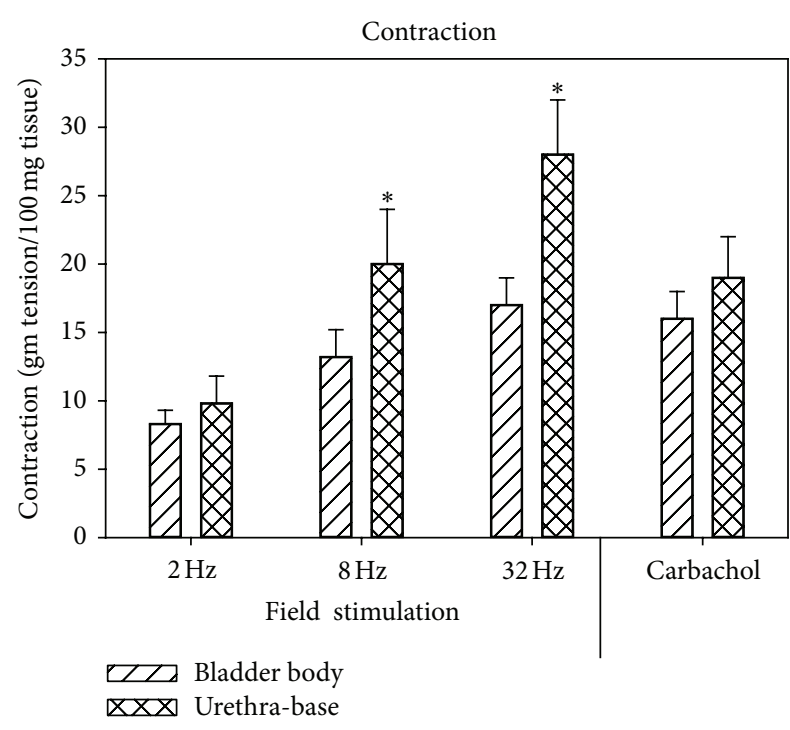

FIGURE 1: Contractile responses to field stimulation and carbachol for the bladder body and base-urethral strips. Each bar is the mean \pm SEM of 6 individual rabbits. ${ }^{*}=$ significantly different from bladder body, $P<0.05$.

\section{Results}

The contractile responses of the bladder body and baseurethra tissue are presented in Figure 1. The responses of the base-urethral strips to 8 and $32 \mathrm{~Hz}$ were significantly higher than the responses of the bladder body strips for each stimulation. Figure 2 shows the contractile responses after recovery from ischemia/reperfusion $(\mathrm{I} / \mathrm{R})$ as the percent of the control response (before I/R). Whereas the recovery of the strips to field stimulation reached only $20 \%$ of the control response, the recovery of carbachol reached $60 \%$ of control. The recovery of the base-urethral strips was significantly higher to field stimulation than were the bladder body strips.

Figures 3 and 4 show the responses of the bladder body (Figure 3) and base-urethra (Figure 4) to $\mathrm{H}_{2} \mathrm{O}_{2} \cdot \mathrm{H}_{2} \mathrm{O}_{2}$ produced a progressive decrease to all forms of stimulation to approximately the same level for both tissues except for the $32 \mathrm{~Hz}$ stimulation which was less sensitive to $\mathrm{H}_{2} \mathrm{O}_{2}$ than all other forms of stimulation. Interestingly, carbachol was more sensitive to hydrogen peroxide than it was to I/R.

Malondialdehyde (MDA) is a biomarker for peroxidative damage to lipids $[24,26,27]$. In both in vitro $\mathrm{I} / \mathrm{R}$ and $\mathrm{H}_{2} \mathrm{O}_{2}$ experiments, MDA levels were significantly elevated in the experimental strips compared to control tissue with higher levels seen in the oxidized base-urethra compared to the bladder body. Significantly, higher levels were seen in the $\mathrm{H}_{2} \mathrm{O}_{2}$ experiments than in the I/R experiments (Figure 5).

The total antioxidant activity levels (AA) for all tissue in both experiments did not differ significantly. The data has been normalized to control $=100$ to allow for a better view of the effect of oxidation on the AA (Figure 6). It should be noted however that AA of the $\mathrm{H}_{2} \mathrm{O}_{2}$ oxidized tissues were significantly lower than the AA of the oxidized I/R tissues.

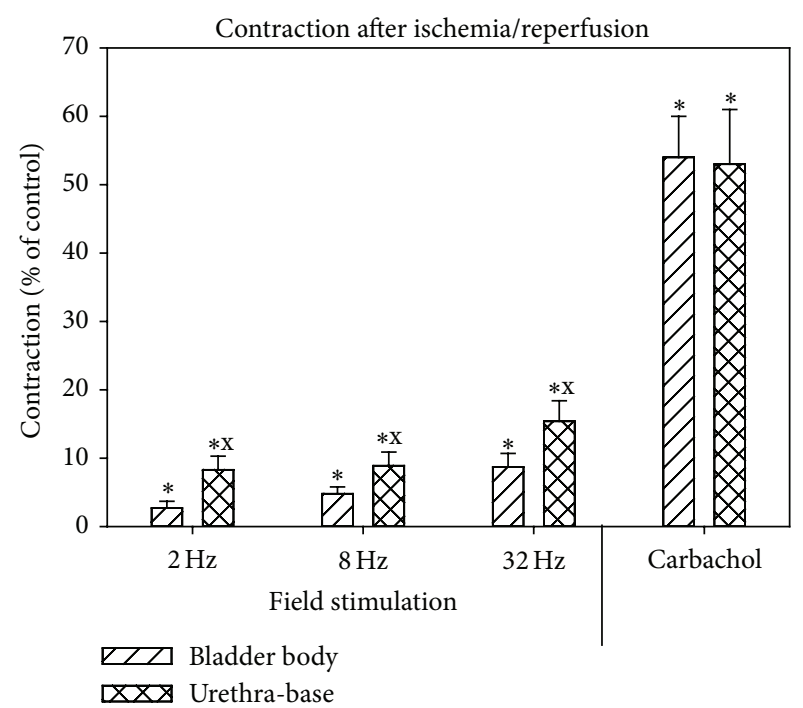

FIGURE 2: Effect of ischemia/reperfusion on the contractile responses to field stimulation and carbachol for the bladder body and base-urethral strips. Each bar is the mean \pm SEM of 3 individual rabbits. ${ }^{*}=$ significantly different from control; $\mathrm{x}=$ significantly different from bladder body, $P<0.05$.

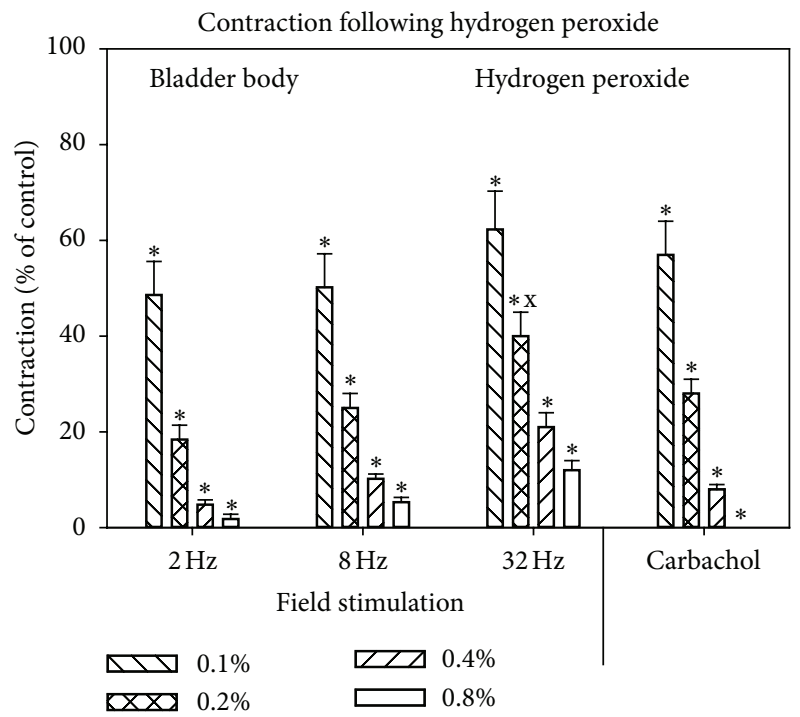

FIGURE 3: Effect of hydrogen peroxide on the contractile responses to field stimulation and carbachol for the bladder body. Each bar is the mean \pm SEM of 3 individual rabbits. ${ }^{*}=$ significantly different from control; $\mathrm{x}=$ significantly different from the effects of $0.2 \%$ hydrogen peroxide on other forms of stimulation, $P<0.05$.

The AA of the organ bath buffer were elevated in the in vitro $\mathrm{H}_{2} \mathrm{O}_{2}$ experiment when the concentration of $\mathrm{H}_{2} \mathrm{O}_{2}$ was increased above $0.2 \%$. The AA at $0.4 \%$ and $0.8 \% \mathrm{H}_{2} \mathrm{O}_{2}$ for both bladder body and urethra-base were significantly higher than the control levels (Figure 7). The AA of the organ bath buffers from the I/R experiment were not significantly higher than control (Figure 8). 


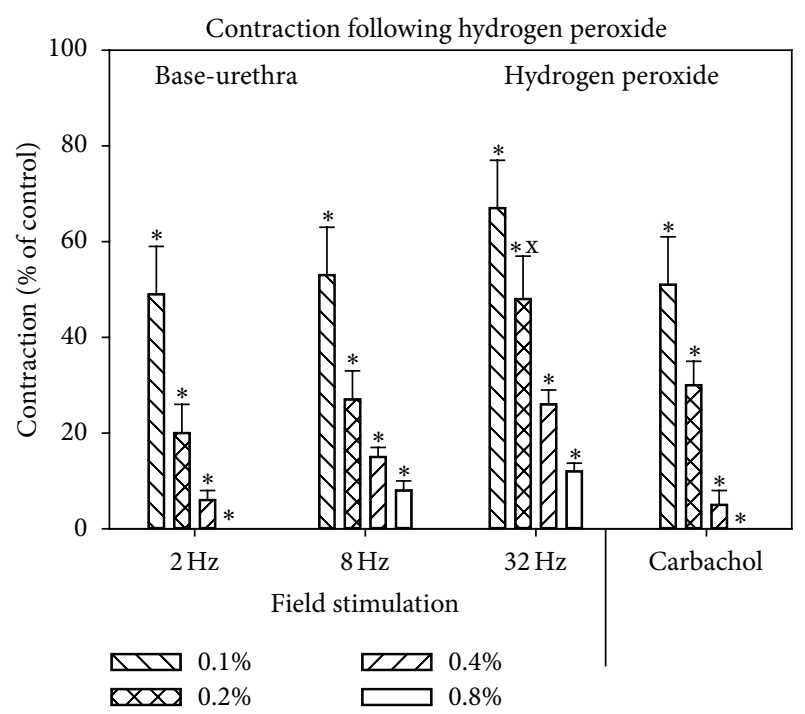

FIGURE 4: Effect of hydrogen peroxide on the contractile responses to field stimulation and carbachol for the bladder base-urethra. Each bar is the mean \pm SEM of 3 individual rabbits. ${ }^{*}=$ significantly different from control; $\mathrm{x}=$ significantly different from the effects of $0.2 \%$ hydrogen peroxide on other forms of stimulation, $P<0.05$.

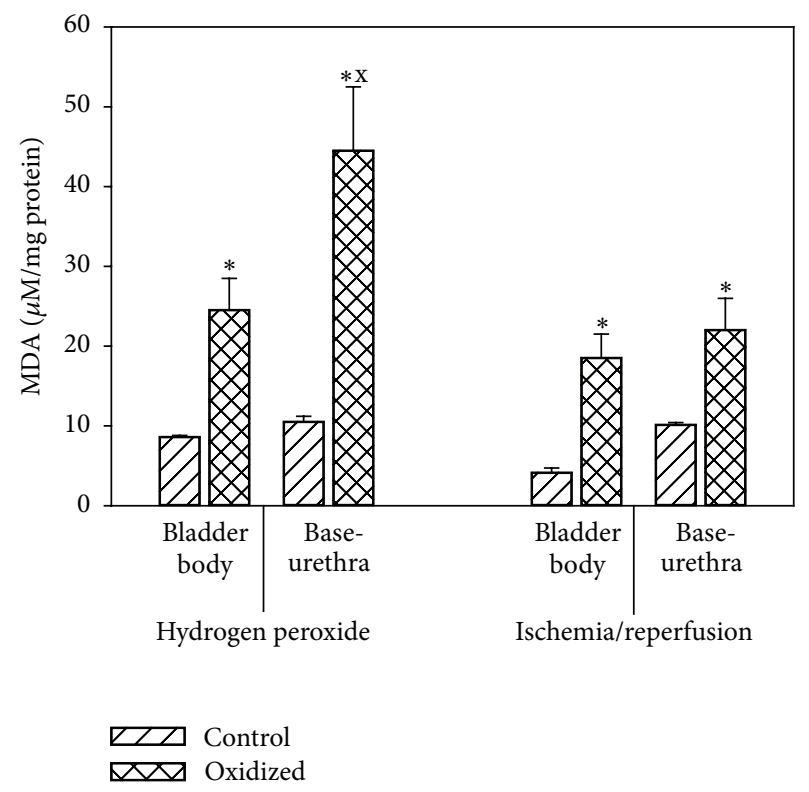

FIGURE 5: Effect of hydrogen peroxide and ischemia/reperfusion on MDA concentrations. Each bar is the mean \pm SEM of 3 individual rabbits. ${ }^{*}=$ significantly different from control; $\mathrm{x}=$ significantly different from bladder body, $P<0.05$.

\section{Discussion}

The specific aim of the current study was to directly compare the two models of in vitro oxidative damage. The data from our contractility studies revealed that the two models have very different effects on the contractile responses to FS and to carbachol. The response to FS was inhibited to a significantly greater degree than to carbachol in the I/R experiment than

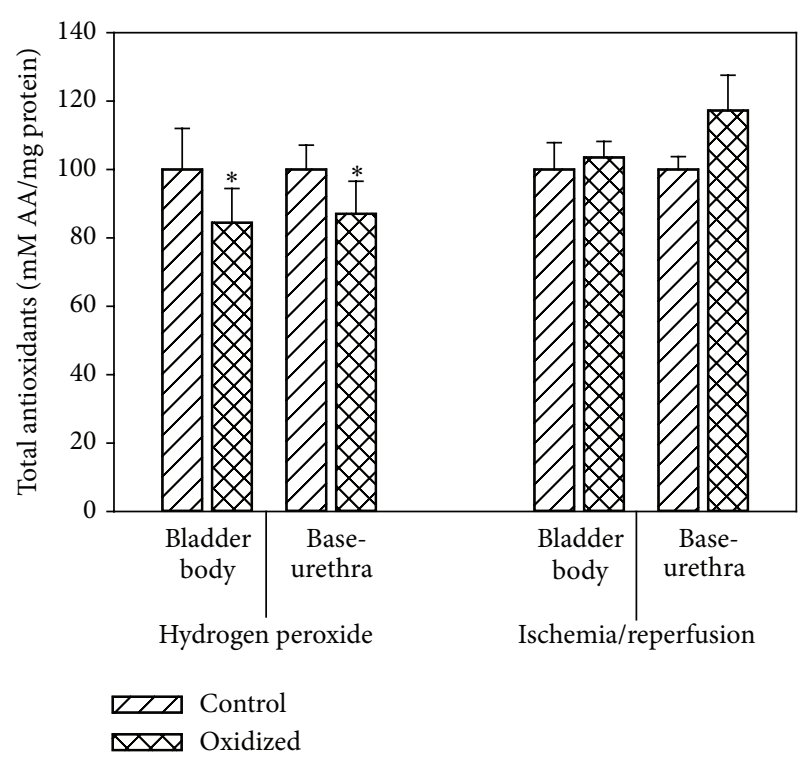

FIGURE 6: Total antioxidants of bladder body and base-urethra before and after hydrogen peroxide and ischemia/reperfusion. Each bar is the mean \pm SEM of 3 individual rabbits. ${ }^{*}=$ significantly different from oxidized body and base-urethra following ischemia/reperfusion, $P<0.05$.

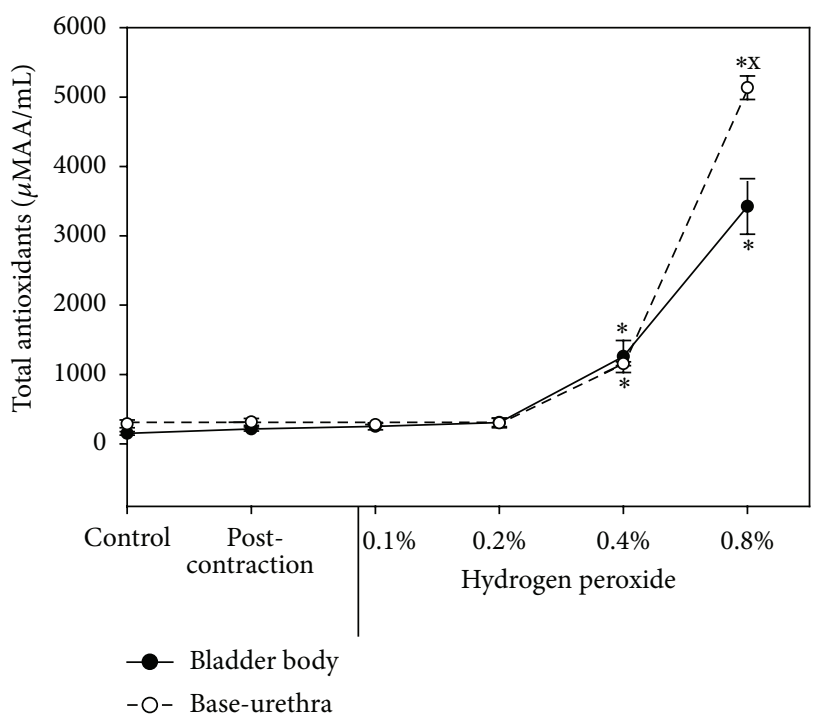

FIGURE 7: Total antioxidants in the bath water following hydrogen peroxide. Each symbol is the mean \pm SEM of 3 individual rabbits. ${ }^{*}$ = significantly different from control, $\mathrm{x}=$ significantly different from bladder body, $P<0.05$.

the $\mathrm{H}_{2} \mathrm{O}_{2}$ experiment. $\mathrm{H}_{2} \mathrm{O}_{2}$ produced a similar decrease in bladder tissue contractility response to both carbachol and field stimulation. The significance of this is that I/R targets the synapse and synaptic transmission to a greater extent than it does the muscarinic receptor or the cell membrane, whereas $\mathrm{H}_{2} \mathrm{O}_{2}$ targets the synapse equally to the muscarinic receptor [28]. 


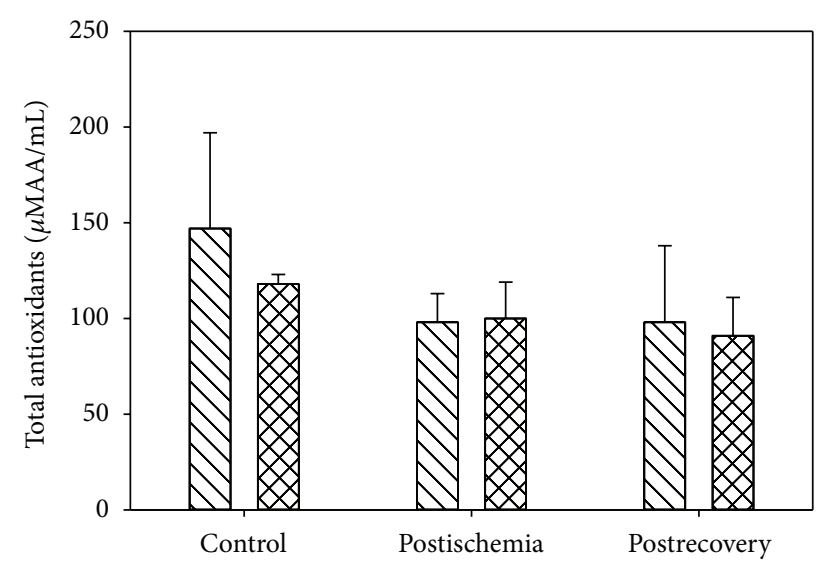

$\triangle \backslash \nabla$ Bladder body

FIgURE 8: Total antioxidants in the bath water following ischemia/reperfusion. Each symbol is the mean \pm SEM of 3 individual experiments.

Furthermore, our biochemical analyses revealed that MDA levels were significantly higher for both bladder body and base-urethra in the hydrogen peroxide experiment when compared to those of the I/R experiment. MDA is a biomarker for oxidative damage and a product of fatty acid lipid peroxidation induced by reactive oxygen species [24, 26, 27]. Interestingly, in the $\mathrm{H}_{2} \mathrm{O}_{2}$ experiment the generation of MDA in the base-urethra tissue was significantly higher than the body tissue. In the I/R experiment, the MDA response was approximately the same for the two tissues showing another difference in the responses to the two forms of oxidative stress that were utilized.

Since the $\mathrm{H}_{2} \mathrm{O}_{2}$ is added to the organ bath in the contractile studies, the intracellular oxidative effects cannot be directly compared to the I/R induced oxidative stress. However, $\mathrm{H}_{2} \mathrm{O}_{2}$ is a naturally occurring oxidative compound. Physiologically, superoxide dismutase (SOD) will metabolize superoxide to hydrogen peroxide $\left(\mathrm{H}_{2} \mathrm{O}_{2}\right)$, which in turn will be converted to $\mathrm{O}_{2}$ and $\mathrm{H}_{2} \mathrm{O}$ by catalase. Pathological conditions can significantly alter the concentrations of SOD and catalase and thus result in the accumulation of $\mathrm{H}_{2} \mathrm{O}_{2}$ which is a strong oxidant capable of causing oxidative damage [21]. Both models have been utilized in experimental models of oxidative stress in the bladder $[29,30]$.

It should also be noted that at higher concentrations of $\mathrm{H}_{2} \mathrm{O}_{2}$ (above $0.2 \%$ ), total antioxidant levels (AA) were elevated in the organ bath buffers, while levels in the I/R experiments remained constant. The fact that the AA of the oxidized tissues from the $\mathrm{H}_{2} \mathrm{O}_{2}$ experiments was significantly higher than the AA of the oxidized tissue from the I/R experiment is consistent with the leakage of the AA from the tissue to the bath in the $\mathrm{H}_{2} \mathrm{O}_{2}$ experiments. Consistent with this is the demonstration that in the $\mathrm{H}_{2} \mathrm{O}_{2}$ experiments, the AA concentrations of the oxidized tissues were significantly lower than the oxidized tissues of the I/R experiment.

\section{Conclusions}

Both forms of in vitro oxidative stress resulted in significant decreases in contractility and increased lipid peroxidation. However, the results clearly demonstrate that $\mathrm{I} / \mathrm{R}$ and $\mathrm{H}_{2} \mathrm{O}_{2}$ act significantly differently on the bladder and thus should not be used interchangeably. In general, since in vivo models of bladder dysfunction such as partial outlet obstruction inhibit field-stimulated contraction to a significantly greater degree than carbachol and $\mathrm{KCl}$ inhibit, it shows that in vitro ischemia/reperfusion would be closer to obstructive bladder dysfunction than $\mathrm{H}_{2} \mathrm{O}_{2}$.

\section{Acknowledgments}

This material is based upon work supported in part by the Office of Research and Development Department of the Veterans Affairs and in part by the Capital Region Medical Research Foundation.

\section{References}

[1] C. M. Gomes, S. Arap, and F. E. Trigo-Rocha, "Voiding dysfunction and urodynamic abnormalities in elderly patients," Revista do Hospital das Clinicas, vol. 59, no. 4, pp. 206-215, 2004.

[2] G. Chen, "Pelvic floor dysfunction in aging women," Taiwanese Journal of Obstetrics and Gynecology, vol. 46, no. 4, pp. 374-378, 2007.

[3] J. A. Hypolite, P. A. Longhurst, C. Gong, J. Briscoe, A. J. Wein, and R. M. Levin, "Metabolic studies on rabbit bladder smooth muscle and mucosa," Molecular and Cellular Biochemistry, vol. 125, no. 1, pp. 35-42, 1993.

[4] J. D. Lilly and C. L. Parsons, "Bladder surface glycosaminoglycans is a human epithelial permeability barrier," Surgery Gynecology and Obstetrics, vol. 171, no. 6, pp. 493-496, 1990.

[5] C. L. Parsons, D. Boychuk, S. Jones, R. Hurst, and H. Callahan, "Bladder surface glycosaminoglycans: an epithelial permeability barrier," Journal of Urology, vol. 143, no. 1, pp. 139-142, 1990.

[6] M. R. Ruggieri, P. M. Hanno, and S. Samadzadeh, "Heparin inhibition of increased bacterial adherence following overdistension, ischemia and partial outlet obstruction of the rabbit urinary bladder," Journal of Urology, vol. 136, no. 1, pp. 132-135, 1986.

[7] M. R. Ruggieri, R. M. Levin, P. M. Hanno, B. A. Witkowski, H. S. Gill, and G. F. Steinhardt, "Defective antiadherence activity of bladder extracts from patients with recurrent urinary tract infection," Journal of Urology, vol. 140, no. 1, pp. 157-159, 1988.

[8] A. Rehfuss, C. Schuler, C. Maxemous, R. E. Leggett, and R. M. Levin, "Cyclical estrogen and free radical damage to the rabbit urinary bladder," International Urogynecology Journal and Pelvic Floor Dysfunction, vol. 21, no. 4, pp. 489-494, 2010.

[9] W. J. Badger, C. Whitbeck, B. Kogan, P. Chichester, and R. M. Levin, "The immediate effect of castration on female rabbit bladder blood flow and tissue oxygenation," Urologia Internationalis, vol. 76, no. 3, pp. 264-268, 2006.

[10] M. H. Parekh, P. Chichester, R. W. Lobel, K. Aikawa, and R. M. Levin, "Effects of castration on female rabbit bladder physiology and morphology," Urology, vol. 64, no. 5, pp. 1048-1051, 2004.

[11] R. M. Levin, A. J. Wein, K. Whitmore, F. C. Monson, B. A. W. McKenna, and M. R. Ruggieri, “Trypan blue as an indicator of 
urothelial integrity," Neurourology and Urodynamics, vol. 9, no. 3, pp. 269-279, 1990.

[12] F. C. Monson, A. J. Wein, B. A. W. McKenna, K. Whitmore, and R. M. Levin, "Indigocarmine as a quantitative indicator of urothelial integrity," Journal of Urology, vol. 145, no. 4, pp. 842845, 1991.

[13] S. A. Zderic, R. M. Levin, and A. Wein, "Voiding function and dysfunction: a relevant anatomy, physiology, and pharmacology, and molecular biology," in Adult and Pediatric Urology, J. Y. Gillenwater, J. T. Grayhack, S. S. Howard, and J. D. Duckett, Eds., Mosby Year Book Medical Publishers, Chicago, Ill, USA, 1996.

[14] K. Aikawa, T. Sugino, S. Matsumoto, P. Chichester, C. Whitbeck, and R. M. Levin, "The effect of ovariectomy and estradiol on rabbit bladder smooth muscle contraction and morphology," Journal of Urology, vol. 170, no. 2, part 1, pp. 634-637, 2003.

[15] T. Tammela, A. J. Wein, F. C. Monson, and R. M. Levin, "Urothelial permeability of the isolated whole bladder," Neurourology and Urodynamics, vol. 12, no. 1, pp. 39-47, 1993.

[16] H. Yu, C. Chien, Y. Lai et al., "Hypoxia preconditioning attenuates bladder overdistension-induced oxidative injury by up-regulation of Bcl-2 in the rat," Journal of Physiology, vol. 554, no. 3, pp. 815-828, 2004.

[17] P. Irwin and N. T. M. Galloway, "Impaired bladder perfusion in interstitial cystitis: a study of blood supply using laser Doppler flowmetry," Journal of Urology, vol. 149, no. 4, pp. 890-892, 1993.

[18] M. A. Pontari, P. M. Hanno, and M. R. Ruggieri, "Comparison of bladder blood flow in patients with and without interstitial cystitis," Journal of Urology, vol. 162, no. 2, pp. 330-334, 1999.

[19] B. Chughtai, A. Mannikarottu, R. M. Levin, P. Chichester, C. Schuler, and E. De, "Ischemic etiology of incontinence in women, a theory and a review," The Open Urology \& Nephrology Journal, vol. 1, pp. 1-8, 2008.

[20] W. Lin, A. Rehfuss, C. Schuler, and R. M. Levin, "Effect of coenzyme Q10 and alpha-lipoic acid on response of rabbit urinary bladder to repetitive stimulation and in vitro ischemia," Urology, vol. 72, no. 1, pp. 214-219, 2008.

[21] J. G. Scandalios, "Oxidative stress responses-what have genome-scale studies taught us?” Genome Biology, vol. 3, no. 7, article 1019, 2002.

[22] R. Apak, K. Güçlü, M. Özyürek, B. Bektaşoǧlu, and M. Bener, "Cupric ion reducing antioxidant capacity assay for food antioxidants: vitamins, polyphenolics, and flavonoids in food extracts," Methods in Molecular Biology, vol. 477, pp. 163-193, 2008.

[23] H. Bean, F. Radu, E. De, C. Schuler, R. E. Leggett, and R. M. Levin, "Comparative evaluation of antioxidant reactivity within obstructed and control rabbit urinary bladder tissue using FRAP and CUPRAC assays," Molecular and Cellular Biochemistry, vol. 323, no. 1-2, pp. 139-142, 2009.

[24] M. Conti, P. C. Morand, P. Levillain, and A. Lemonnier, "Improved fluorometric determination of malonaldehyde," Clinical Chemistry, vol. 37, no. 7, pp. 1273-1275, 1991.

[25] F. Radu, R. E. Leggett, C. Schuler, and R. M. Levin, “The effect of in vitro ischemia/reperfusion on contraction, free fatty acid content, phospholipid content, and malondialdehyde levels of the rabbit urinary bladder," Molecular and Cellular Biochemistry, vol. 346, no. 1-2, pp. 179-186, 2011.

[26] C. Jo and D. U. Ahn, "Fluorometric analysis of 2-thiobarbituric acid reactive substances in turkey," Poultry Science, vol. 77, no. 3, pp. 475-480, 1998.
[27] W. Wasowicz, J. Neve, and A. Peretz, “Optimized steps in fluorometric determination of thiobarbituric acid-reactive substances in serum: importance of extraction $\mathrm{pH}$ and influence of sample preservation and storage," Clinical Chemistry, vol. 39, no. 12, pp. 2522-2526, 1993.

[28] R. de Jongh, R. de Jongh, G. R. Haenen et al., "Oxidative stress reduces the muscarinic receptor function in the urinary bladder," Neurourology and Urodynamics, vol. 26, no. 2, pp. 302308, 2007.

[29] K. Aikawa, R. E. Leggett, and R. M. Levin, "Effect of age on hydrogen peroxide mediated contraction damage in the male rat bladder," Journal of Urology, vol. 170, no. 5, pp. 2082-2085, 2003.

[30] C. A. Agartan, R. E. Leggett, B. A. Kogan, and R. M. Levin, "Effect of age on the response to in vitro ischemia and reperfusion of the rabbit bladder," Urologia Internationalis, vol. 78, no. 2, pp. 155-159, 2007. 


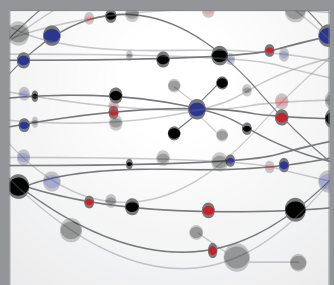

The Scientific World Journal
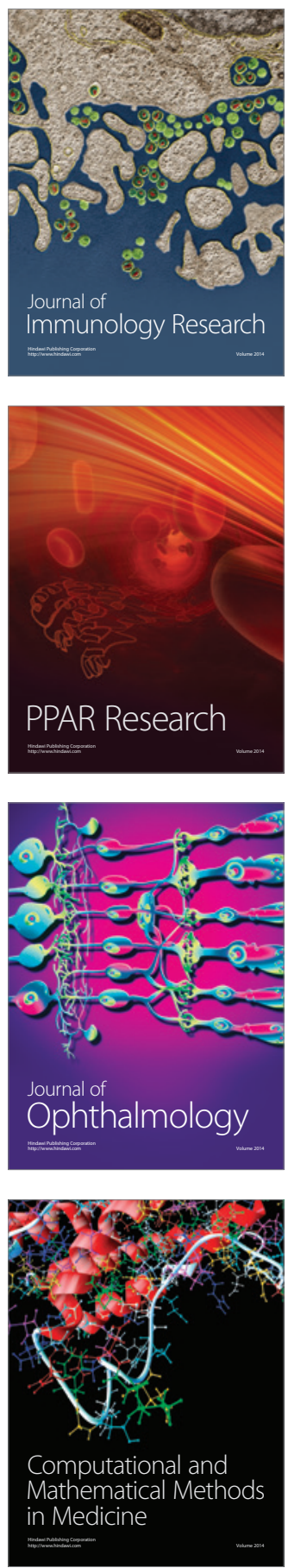

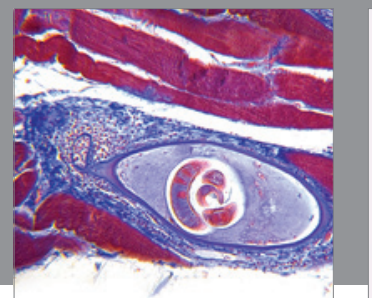

Gastroenterology

Research and Practice
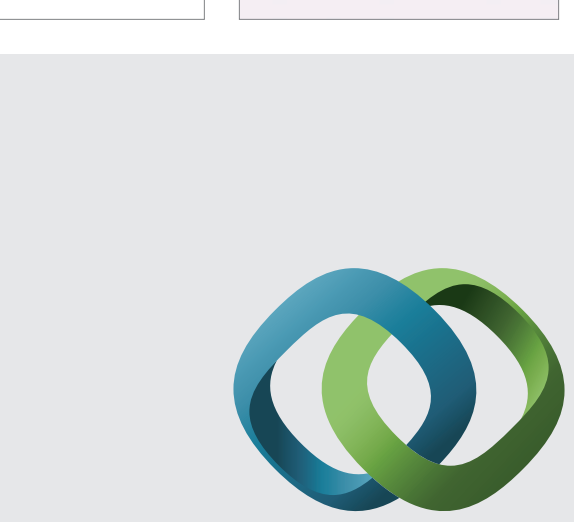

\section{Hindawi}

Submit your manuscripts at

http://www.hindawi.com
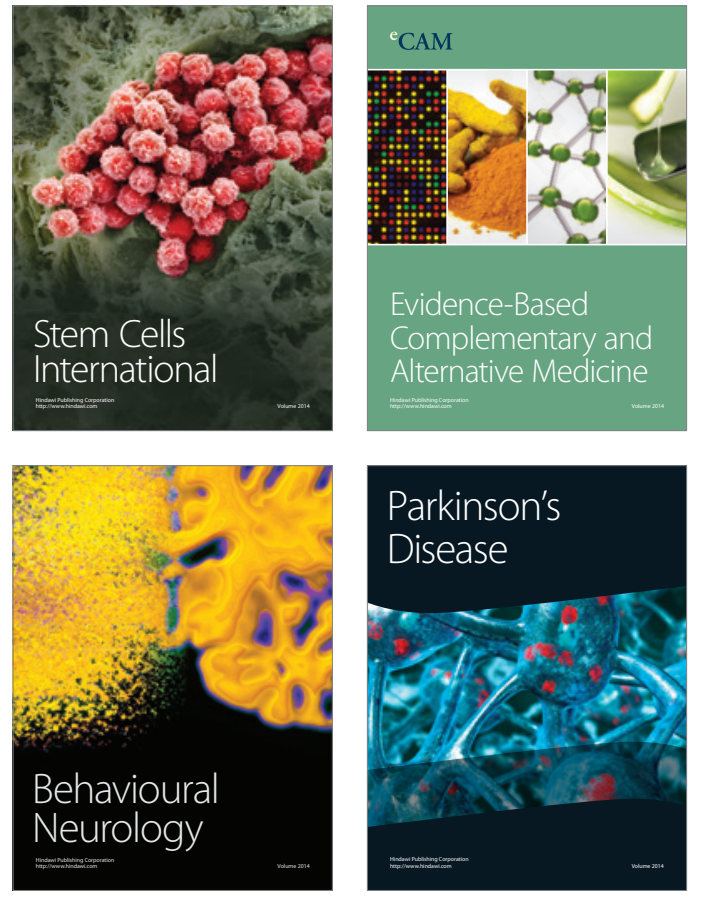
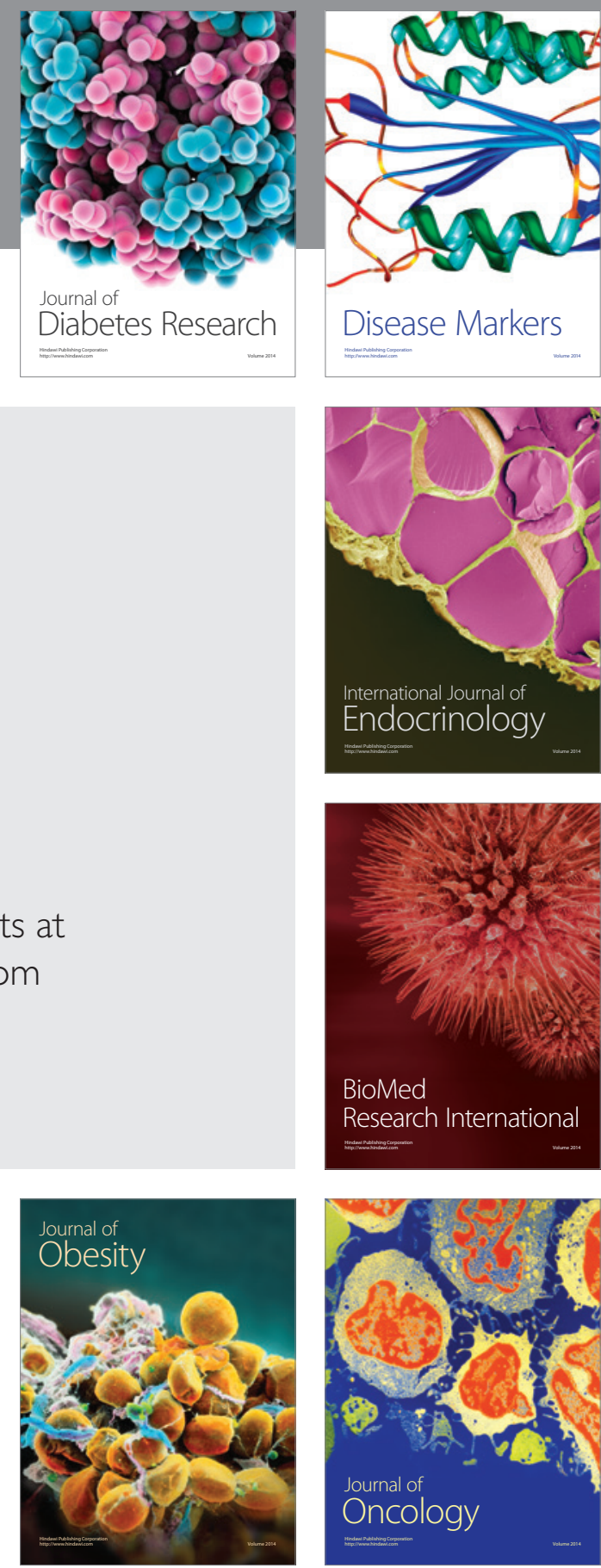

Disease Markers
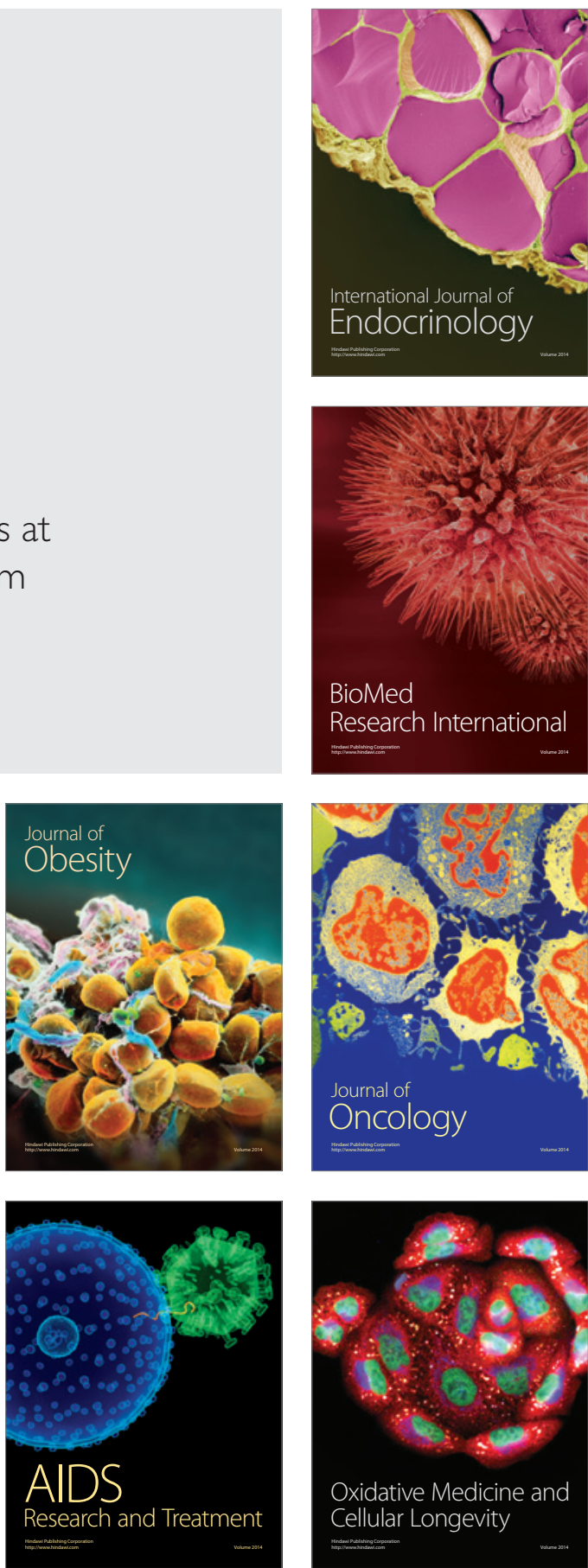